\title{
PEMBERDAYAAN KELOMPOK INFORMASI MASYARAKAT (STUDI KASUS: KECAMATAN TURI DAN KECAMATAN GAMPING, KABUPATEN SLEMAN)
}

\author{
Oleh : Maryatun* dan Lasa Hs.*
}

\begin{abstract}
This study aims to describe the process and implementation of empowerment program that have bee done by KIM to increase information access to improve the community welfare, identify the most influential program and obstacles faced in this implementation.

The objects of this study are Kelompok Informasi Masyarakat (KIM) in Sleman; one case in Turi whic represents the developed KIM, and the other case in Gamping which represents the developing KIM. Th. purpose of the empowerment of KIM is how the empowerment runs well through the development process 1 improve the importance of information awareness, increase information access and ihfonnation empowermes through the group.

From the data analysis, the community empowerment process is done through several stages (1 awareness (2) capacity (3) support (4) performing the action and implementation; (5) evaluation. Meanwhile the programs done by KIM cover 1) increasing information access media, 2) socialization, 3) participation in government activities, 4) Opening the network to the institutions / agencies / allied organisations 5) trainings 6) participating in exhibition, 7) gaining the capital 8) Conducting assistance, 9) Following the comparativ, study, 10) Conducting formal meeting with the legislative commission, and, 11) media report. Those activities indeed, can give awareness to the community that information can be useful to reduce uncertainty and can bs used to make the best decision immediately. The community becomes more creative in running their busines: activities that can be able to increase their welfare.

The developed KIM has an easy access to information from various sources, has a capability to acces: information, discuss, and implements in a variety of business activities so that it can improve the communit] welfare, has cooperation network with related institutions, has a wider business activities, has mort implementation programs, and has an ability to solve their own problems.
\end{abstract}

Keywords: Commun ity empowerment, Kelompok Informasi Masyarakat (KIM), information access, community welfare.

* Pustakawan UGM

\section{PENDAHULUAN}

Pembubaran Departemen Penerangan pada tanggal 28 Oktober 1999 mengakibatkan terjadinya kekosongan infrastruktur komunikasi dan informasi di daerah. Rantai informasi pemerintah kepada masyarakat menjadi putus. Juru Penerang (Jupen) dan Kelompencapir sebagai institusi semi-masyarakat ikut dibubarkan, padahal masyarakat masih membutuhkannya. Sebagian besar masyarakat yang tinggal di pedesaan belum mampu mengakses informasi. Hal tersebut disebabkan karena kurangnya infrastruktur yang memadai, tingkat pendidikan yang rendah, kondisi ekonon serta budaya pada masyarakat.

Beberapa program penyuluhan $\mathrm{da}$ penerangan kepada masyarakat tidak ada lą yang merasa bertanggung jawab, sehingg semakin hari semakin sulit untuk memperole informasi yang terkait dengan peningkatan usah serta kualitas hidup masyarakat. Masyaraka pedesaan memerlukan informasi perkembanga: pasar untuk produk mereka, perkembanga teknologi pertanian dan perikanan, teknolog pengembangan produk dan masalah-masala] pengelolaan usaha kecil. Ketika permasalaha] nasional muncul, seperti kenaikan harga $\mathrm{BBM}$ 
global warming, isu wabah flu burung, dampak krisis ekonomi global yang disinyalir berdampak pada krisis ekonomi pedesaan akibat dampak penurunan nilai rupiah dan peningkatan harga domestik (www.ugm.ac.id, 17-10-2008), mereka mengalami ketidakpastian informasi.

Untuk mengisi kekosongan infrastruktur tersebut, Direktorat Kelembagaan Sosial Departemen Komunikasi dan Informasi memandang perlu adanya pemberdayaan masyarakat dalam rangka penyaluran informasi dan aspirasi masyarakat. Kemudian muncul Kelompok Informasi Masyarakat (KIM) yang merupakan reaktualisasi dari Kelompencapir maupun dari hasil pembentukan kelompok baru sebagai alternatif pemberdayaan masyarakat di bidang informasi yang berbasis dari inisiatif masyarakat.

Menurut data yang ada, di Kabupaten Sleman terdapat 17 Kelompok Informasi Masyarakat. Namun demikian hingga saat ini keberadaannya belum banyak dikenal oleh masyarakat. KIM yang sudah terbentuk juga belum banyak berperan dalam memediasi masyarakat dengan pihak-pihak lain, seperti perguruan tinggi, lembaga atau pusat-pusat penelitian, perpustakaan, lembaga donor, LSM serta lembaga-lembaga lain baik bersifat profit maupun nonprofit. Pola komunikasi melalui kelompok masyarakat belum dilakukan secara optimal. Seharusnya KIM yang salah satu fungsinya sebagai lembaga yang memiliki nilai ekonomi, melalui informasi yang diperoleh dari berbagai sumber, KIM dapat menerapkannya dalam berbagai aktivitas seperti, pertanian, perdagangan, peternakan, industri dan mendapatkan tambahan pendapatan dari aktivitas tersebut.

Dalam penelitian ini penulis ingin mengatasi persoalan-persoalan sebagai berikut:

1. Bagaimana proses pemberdayaan masyarakat yang dilakukan oleh Kelompok Informasi Masyarakat?

2. Apa saja variasi program pemberdayaan yang telah dilakukan oleh Kelompok Informasi Masyarakat terhadap peningkatan akses informasi untuk menambah kesejahteraan?
3. Apa perbedaan dan persamaan progr tersebut pada kelompok yang lebih maju dibandingkan dengan kelomr yang belum maju?

\section{TINJAUAN PUSTAKA \\ Pemberdayaan Masyarakat}

Secara etimologi pemberdayaan bera dari kata dasar "daya", yang berarti kemampı melakukan sesuatu (KBBI, 2005), sedangl pemberdayaan berarti proses, cara, perbua memberdayakan.

Pengertian "proses" menurut Sulistiy: (2004) menunjuk pada serangkaian tindakan a langkah-langkah yang dilakukan sec kronologis, sistematis yang mencerminl tahapan untuk mengubah pihak yang kurang a belum berdaya menuju keberdayaan.

Menurut Wrihatnolo, (2007) bah sebagai sebuah proses, pemberdayaar mempunyai tiga tahapan:

(1) Penyadaran, yaitu target yang al diberdayakan diberikan penyadaran bah mereka dapat menjadi berdaya, dan dapat dilakukan apabila mer mempunyai kapasitas untuk keluar ( ketidakberdayaannya;

(2) Pengkapasitasan, yaitu pemberian kapas pada individu atau kelompok agar man menerima daya atau kekuasaan $y:$ berupa pelatihan, seminar, dan sejenisny:

(3) Pemberian daya (empowerment), yaitu tar diberikan daya, kekuasaan, otoritas, a peluang sesuai dengan kecakapan $\mathrm{y}_{\mathrm{i}}$ telah dimiliki.

Hogan dalam Adi, 2008 menggambarl proses pemberdayaan yang berkesinambun: sebagai suatu siklus yang terdiri dari li tahapan, yaitu:

1) menghadirkan kembali pengalaman ya memberdayakan

memberdayakan;

2) mendiskusikan alasan yang menyebab. mengapa terjadi pemberdayaan penidakberdayaan;

3) mengidentifikasi suatu masalah;

4) mengidentifikasi basis daya yang bermak untuk melakukan perubahan; 
5) mengembangkan rencana aksi dan mengimplementasikan.

Konsep pemberdayaan masyarakat menurut Depkominfo (2006) bahwa pemberdayaan terjadi melalui proses peningkatan kesadaran pentingnya informasi, peningkatan akses, dan pendayagunaan informasi melalui kelompok. Keberhasilan pemberdayaan masyarakat memerlukan keterlibatan dan hubungan yang bersifat sinergis antar segenap komponen (stakeholder) dengan fungsi dan peran masing-masing sebagai bagian dari sistem, baik masyarakat, pemerintah maupun pihak terkait lainnya (Herman, 2007: 33).

Dharmawan mendefinisikan makna Jemberdayaan sebagai:

'a process of having enough energy enabling veople to expand their capabilities, to have jreater bargaining power, to make their own tecisions, and to more easily access to a source ff better living"

Menurut Sumodingingrat

(1999), Jemberdayaan masyarakat berarti meningkatkan semampuan atau meningkatkan kemandirian nasyarakat melalui: 1) penciptaan suasana atau iklim yang memungkinkan masyarakat serkembang; 2) peningkatan kemampuan nasyarakat dalam pembangunan melalui Jerbagai bantuan dan pelatihan, pembangunan rasarana dan sarana baik fisik maupun sosial; 3 ) Jerlindungan melalui pemihakan kepada yang emah untuk mencegah persaingan yang tidak seimbang, dan menciptakan kemitraan yang saling menguntungkan.

Menurut laporan World Bank, 2005 Jahwa ada empat elemen dasar dari Jemberdayaan yaitu: (1) akses pada informasi; 2) partisipasi; (3) akuntanbilitas; dan (4) rapasitas organisasi lokal. Jadi akses informasi nerupakan salah satu komponen dari Jemberdayaan. Masyarakat yang diberdayakan nemerlukan ketersediaan informasi dari agen jemberdaya.

Darwanto, 2004 menyebutkan bahwa insur-unsur pemberdayaan masyarakat pada imumnya adalah: (1) inklusi dan partisipasi; (2) kkses pada informasi; (3) kapasitas organisasi okal; dan (4) profesionalitas pelaku pemberdaya.
Keempat unsur tersebut saling terkiait dan saling mendukung.

\section{Kelompok Informasi Masyarakat (KIM)}

Kelompok Informasi Masyarakat (KIM) adalah sekumpulan individu yang berinteraksi dengan tujuan memecahkan masalah kehidupan dengan mengakses, mengolah dan memanfaatkan informasi yang diperoleh dari media massa dan berbagai sumber informasi serta mendesiminasikan kepada sesama anggota kelompok dan kepada masyarakat (Wahyudiyono, 2008).

Sesuai dengan kerangka acuan arah pengembangan dan pemberdayaan Kelompok Informasi Masyarakat (KIM) yang dikeluarkan oleh Direktorat Jenderal Sarana Komunikasi dan Diseminasi Informasi, maka KIM mempunyai visi untuk mewujudkan KIM yang inovatif dalam meningkatkan nilai tambah bagi masyarakat melalui pendayagunaan informasi dan komunikasi dalam rangka mencapai masyarakat informasi yang sejahtera, sedangkan fungsi KIM sebagai wahana informasi, mitra dialog dengan pemerintah dalam merumuskan kebijakan publik, sarana peningkatan literasi masyarakat, dan sebagai lembaga yang memiliki nilai ekonomi. Apabila dilihat dari kegiatan KIM, Ropingan, (2007) menemukan konsep-konsep intepretatif KIM sebagai berikut: (1) konsep demokrasi; (2) konsep dampak dan struktur organisasi; (3) konsep aspirasi masyarakat; dan (4) konsep arus informasi.

Berger dan Neuhaus (dalam Nugroho, 1997), secara konkret menunjuk lembagalembaga keluarga, ketetanggaan, keagamaan, dan lembaga keswadayaan merupakan institusiinstitusi mediasi untuk membantu pemberdayaan masyarakat. Oleh karena itu pemberdayaan KIM yang tumbuh dari bawah perlu didorong sebagai alternatif dalam rangka mengatasi kesenjangan informasi kepada masyarakat dan sebagai strategi dalam upaya kelancaran arus informasi di daerah pedesaan (Ropingan, 2007).

\section{Akses Informasi}

Indikator tingkat akses masyarakat terhadap informasi menurut Kartono (2004) 
adalah tersedianya informasi yang transparan dan kemampuan masyarakat untuk mengakses informasi. Beberapa kebijakan pemerintah yang seharusnya diketahui oleh masyarakat hanya dapat diakses oleh pihak-pihak tertentu saja. Akses pada informasi dibuka dengan memberikan penjelasan mengenai programprogram pemerintah yang akan dilakukan, norma-norma bermasyarakat yang perlu diketahui, ilmu pengetahuan dasar, hak-hak yang akan mereka peroleh, masalah-masalah yang mungkin dihadapi, dan sebagainya (Darwanto, 2004).

Akses informasi yang diperoleh dari berbagai sumber, masyarakat dapat menerapkannya dalam berbagai aktivitas perdagangan, pertanian, industri sehingga dapat memberikan tambahan pendapatan (Direktorat Jenderal Sarana Komunikasi dan Diseminasi Informasi, 2006).

Akses pada informasi dan teknologi penting untuk diperhatikan karena dapat meningkatkan efisiensi dan mampu berkompetisi dalam ekonomi global, memungkinkan untuk memperoleh berbagai jenis pelayanan lain seperti, kesehatan dan pendidikan yang lebih baik, dan menciptakan sumber-sumber pendapatan dan pekerjaan bagi masyarakat miskin (World Bank, 2006).

\section{Kesejahteraan Masyarakat}

Ravallion \& Loshin; Fuentes \& Rojas; van Pragg, et.al (dalam Maika, 2006), menyebutkan bahwa pengukuran konsep kesejahteraan setidaknya memiliki dua bentuk pengukuran, yaitu objektif dan subjektif.

Nurcholis (2005) memberikan gambaran masyarakat sejahtera adalah masyarakat yang kuantitatif memiliki pendapatan yang layak untuk memenuhi kebutuhan hidup dan mengembangkan diri secara wajar dan secara kualitatif dapat menikmati kehidupan yang yang nyaman secara fisik dan spiritual.

Menurut Ropingan, (2007) dikatakan bahwa sebagai bukti bahwa peran KIM dapat meningkatkan kesejahteraan adalah diadakannya studi banding KIM kabupaten Ponorogo ke Malang. Studi banding tersebut mampu memberikan inspirasi kelompok inforn masyarakat dalam menggali potensi lingkungan sekitar untuk mendapatkan $r$ tambah pemanfaatan fungsi kotoran ternak.

\section{Proposisi}

1) Proses pemberdayaan masyarakat $y$ dilakukan KIM meliputi taha! penyadaran, pengkapasitasan, pembe daya, mengembangkan rencana aksi, evaluasi.

2) Program pemberdayaan yang umum dilakukan oleh KIM mencakup:

Meningkatkan kualitas sumberdaya man melalui pelatihan, pembuatan $p$ informasi, mengikutsertakan KIM da kegiatan pemerintahan, membuka jarir KIM ke institusi terkait dan mengadi studi banding

3) Perbedaan dan persamaan program ters antara KIM yang lebih maju dan belum $r$ pada umumnya, yaitu:

KIM yang lebih maju sudah mem kemudahan akses informasi dari berb sumber, mampu mengakses inforn mendiskusikan, dan mengimplementas dalam berbagai kegiatan usaha, terlibat dalam kegiatan yang diselenggarakan Pemda Sleman, memiliki jaringan kerjas dengan institusi terkait dan mempu kegiatan usaha yang lebih luas.

\section{METODE PENELITIAN}

Penelitian dilakukan dengan menga kasus Kelompok Informasi Masyarakat Wilayah Kabupaten Sleman. Pengaml sampel dalam penelitian ini dilakukan $\mathrm{s} \epsilon$ purposive. KIM di Kecamatan Turi untuk $\mathrm{k}$ yang mewakili KIM yang lebih maju dan ] di Kecamatan Gamping yang mewakili $k$ : KIM yang belum maju. Pengumpulan dilakukan melalui wawancara terbuka de para informan, observasi, dokumentasi, ca arsip dan perangkat fisik dari masing-m: KIM. Temuan kasus pertama dideskrips berdasarkan proposisi yang ada, keml dibawa untuk menguji pada temuan kasus $k$ Temuan kasus pertama dan kedua ditabı 
kemudian dibandingkan, di interpretasikan sehingga memperoleh deskripsi lintas kasus.

\section{HASIL PENELITIAN DAN PEMBAHASAN KIM di Kabupaten Sleman}

Di wilayah kabupaten Sleman telah terbentuk 17 Kelompok Informasi Masyarakat yang berada pada setiap kecamatan. KIM yang terbentuk diberi nama Kelompok Informasi dan Komunikasi Masyarakat yang merupakan forum binaan bagian Humas Kabupaten Sleman. Melalui forum tersebut diharapkan penyebaran informasi tentang berbagai kebijakan pemerintah lebih cepat sampai kepada masyarakat dari pada melalui jalur birokrasi. Oleh sebab itu Humas Kabupaten Sleman melakukan berbagai upaya yang diharapkan mampu mendorong pemberdayaan KIM.

Setiap KIM di wilayah Kabupaten Sleman memperoleh fasilitasi berupa anggaran sebesar Rp. $1.500,000,00$ setiap tahun. Perkembangan KIM di setiap kecamatan dapat diketahui secara periodik melalui penyelenggaraan rapat koordinasi yang diadakan dua sampai tiga kali dalam setiap tahun.

Pemerintah Kabupaten Sleman dalam menyebarkan informasi selain melalui forumforum komunikasi juga menerbitkan Majalah Sembada, Tabloid Varia Slemandantabloid Akar.

Program pemberdayaan juga dilakukan dengan mengikutsertakan KIM dalam kegiatan pemerintahan, kegiatan ini ditegaskan dalam Surat Edaran ke Dinas atau instansi di lingkungan PEMDA yang berisi agar KIM dilibatkan dalam setiap ada acara sosialisasi sehingga informasi yang disampaikan cepat sampai ke masyarakat.

Berbagai produksi dari bidang usaha yang dimiliki KIM dibantu dalam promosi, yaitu melalui pameran potensi yang diselenggarakan Pemerintah Kabupaten Sleman setiap tahun. Masing-masing kelompok diberi fasilitas tempat dan perlengkapan pameran secara gratis.

Upaya pemberdayaan KIM yang telah dilakukan oleh Pemerintah Kabupaten Sleman tidak seluruhnya direspon dengan baik oleh kelompok. Alasannya anggaran yang masih sedikit, pencairan anggaran yang berbelit-belit, dan masih adanya anggapan bahwa pemerintah daerah sebagai sumber dana.

\section{KIM di Kecamatan Turi}

KIM di Kecamatan Turi diberi nama Kelompok Informasi dan Komunikasi Masyarakat (KIKM) Kertomandiri yang anggotanya saling berinteraksi dengan mengakses informasi melalui berbagai media, mengolah, mendiskusikan, mengimplementasikan, dan menyebarluaskan informasi pada masyarakat.

Selain mempunyai fungsi sosial, KIKM Kertomandiri juga mempunyai fungsi profit, yaitu sebagai wadah anggotanya untuk bertukar informasi dalam kegiatan perekonomian, terutama kegiatan usaha yang dimiliki para anggotanya. KIKM menghubungkan anggota dengan pemerintah/swasta atau pihak lain dalam usaha untuk memperoleh penguatan modal, ketrampilan maupun pelatihan, peralatan untuk membantu proses produksi, serta untuk memperoleh peluang pasar bagi produk yang dihasilkan. Ide atau gagasan dibentuknya KIKM Kertomandiri berasal dari para pelaku UMKM (Usaha Mikro Kecil dan Menengah) di Kecamatan Turi yang membutuhkan berbagai informasi berkaitan dengan bidang usahanya. Pada tanggal 12 Juni 2003 KIKM Kertomandiri dideklarasikan pembentukannya. Wilayah kerjanya meliputi Desa Donokerto, Desa Girikerto, Desa Bangunkerta, dan Desa Wonokerto.

Anggota KIKM saat ini berjumlah 42 orang, terdiri dari PNS, pensiunan, petani dan wiraswasta. Mereka tergabung dalam KIKMUMKM Kertomandiri Kecamatan Turi yang menyelenggarakan pertemuan rutin setiap tanggal 20 pukul 14.00 wib. Bidang usaha yang digeluti anggota KIKM Kertomandiri antara lain: 1) bidang pertanian, meliputi budidaya salak pondoh, salak gading, salak organik, dan pembuatan pupuk kompos; 2) bidang peternakan, meliputi usaha ternak kambing PE, pemeliharaan puyuh dan ayam petelur, penggemukan sapi; 3 ) bidang perikanan, meliputi pembesaran lele, nila, gurami, dan mina salak; 4) bidang kerajinan, 
meliputi pembuatan sangkar burung dan pemanfaatan biji salak; 5) bidang ekonomi, meliputi pembuatan aneka olahan salak seperti, dodol salak, wajik salak, suwar-suwir; 6) bidang usaha, meliputi penyulingan minyak nilam dan pembuatan briket arang; 7) bidang kesehatan, yaitu pembuatan minuman kesehatan dengan bahan jamu; 8) bidang pengairan, yaitu pengembangan Sistem Irigasi Pipa (SIP) Tirta Sembada di Dusun Jurugan Bangunkerto Turi; 9) bidang sosial, yaitu pembuatan MCK di Dusun Jurugan Bangunkerto Turi; 10) bidang budaya, yaitu pengembangan seni budaya karawitan dan melestarikan rumah budaya Jawa "Joglo Plawang"; 11) lain-lain, meliputi wirausaha cuci motor, warung sembako, pedagang salak, candak-kulak, warung makan, "eyek" (pedagang keliling).

\section{KIM di Kecamatan Gamping}

Tahun 2005 KIM di Kecamatan Gam] terbentuk atas himbauan dari Humas Pe: Kabupaten Sleman agar di setiap Kecam membentuk KIM untuk membantu pemeri: dalam menyampaikan informasi tentang berb kebijakan pemerintah daerah maupun pemeri: pusat agar lebih cepat sampai ke masyarc Wilayah kerja KIM di Kecamatan Gam] meliputi Desa Trihanggo, Desa Nogotirto, I Banyuraden, Desa Ambarketawang, dan I Balecatur. Keanggotaan KIM di Kecamatan ' melibatkan unsur tokoh masyarakat, Pek Sosial Masyarakat, Karang Taruna, Pega PKK, dan Perwakilan Organisasi Nasiy 'Aisyiah.

\section{Temuan Kasus}

Tabel 1. Proses Pemberdayaan Masyarakat yang dilakukan oleh KIM

\begin{tabular}{|c|c|c|c|}
\hline What & 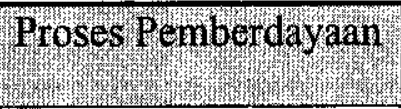 & 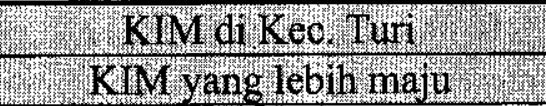 & 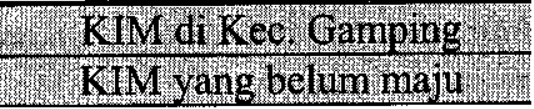 \\
\hline l & Penyadaran & $\begin{array}{l}\text { Sosialisasi tentang pendayagunaan } \\
\text { informasi }\end{array}$ & $\begin{array}{l}\text { Sosialisasi tentang pendayagunaar } \\
\text { informasi }\end{array}$ \\
\hline 2 & Pengkapasitasan & $\begin{array}{l}\text { Anggota dan masyarakat } \\
\text { memperoleh pelatihan dari berbagai } \\
\text { dinas/instansi terkait }\end{array}$ & $\begin{array}{l}\text { Pelatihan dari Dinas Perindustrian } \\
\text { tentang pembuatan kue kering dan } \\
\text { kacang telur }\end{array}$ \\
\hline 3 & Pemberian daya & $\begin{array}{l}\text { - Peningkatan media akses } \\
\text { informasi } \\
\text { - Sosialisasi } \\
\text { - Keikutsertaan dalam kegiatan } \\
\text { pemerintahan } \\
\text { - Membuka jaringan } \\
\text { instansi/lembaga terkait } \\
\text { - Pameran } \\
\text { - Penguatan modal } \\
\text { - Pendampingan } \\
\text { - Studi banding } \\
\text { - Audiensi } \\
\text { - Liputan Media }\end{array}$ & $\begin{array}{l}\text { - } \text { Peningkatan media akses } \\
\text { informasi } \\
\text { - } \text { Sosialisasi } \\
\text { - } \text { Keikutsertaan dalam kegiatar } \\
\text { pemerintahan } \\
\text { - } \text { Membuka jaringan } \\
\text { instansi/lembaga terkait } \\
\text { - Pameran } \\
\text { - Penguatan modal } \\
\text { - Pendampingan }\end{array}$ \\
\hline 4 & $\begin{array}{l}\text { Rencana aksi } \\
\text { implementasi }\end{array}$ & $\begin{array}{l}\text { - Membantu kelompok/masyarakat } \\
\text { dalam merumuskan dan } \\
\text { menentukan program dan kegiatan } \\
\text { untuk mengatasi permasalahan } \\
\text { yang ada. } \\
\text { - Membantu pembuatan proposal } \\
\text { pada penyandang dana. }\end{array}$ & $\begin{array}{l}\text { - Membantu kelompok/masyaraka } \\
\text { dalam merumuskan dar } \\
\text { menentukan program dan kegiatal } \\
\text { untuk mengatasi permasalahas } \\
\text { yang ada. } \\
\text { - Membantu pembuatan proposa } \\
\text { pada penyandang dana. }\end{array}$ \\
\hline 5 & Evaluasi & $\begin{array}{l}\text { - Dilakukan setiap ada } \\
\text { pertemuan rutin kelompok }\end{array}$ & $\begin{array}{l}\text { - Dilakukan setiap ada } \\
\text { pertemuan rutin kelompok } \\
\text { WRSE dan kelompok warga } \\
\text { kurang mampu. } \\
\end{array}$ \\
\hline
\end{tabular}

Sumber: data diolah dari hasil wawancara 
Mereka diharapkan dapat menjadi agen penyebar informasi di masyarakat. Pertemuan anggota direncanakan setiap tiga bulan sekali. Namun dengan alasan kesibukan masing-masing anggota pertemuan tidak dapat rutin diadakan tiga bulan sekali.

Dari tabel di atas terlihat bahwa proses pemberdayaan yang dilakukan KIM di Kecamatan Turi dan KIM di Kecamatan Gamping mempunyai tahapan yang sama, yaitu tahap penyadaran bahwa masyarakat dapat memanfaatkan informasi untuk membantu mengatasi permasalahan sehingga mampu keluar dari ketidakberdayaannya. Tahap pengkapasitasan, yang berupa pelatihan sesuai dengan kebutuhannya, tahap pemberian daya sesuai dengan kecakapan yang telah dimiliki, tahap mengembangkan rencana aksi dan implementasi dan tahap evaluasi. Evaluasi dilakukan oleh para stakeholder dan antar warga masyarakat sendiri secara internal. KIM yang lebih maju mampu memberikan pengkapasitasan dan pemberian daya yang lebih bervariasi. $\mathrm{Hal}$ tersebut disebabkan :

1. Peran motor penggerak KIM di Kecamatan Turi merupakan sosok yang disegani oleh masyarakat dan mantan pejabat di lingkungan Depdiknas, sehingga mudah melakukan lobilobi kepada pejabat Pemda.

2. Anggota KIM di Kecamatan Turi merupakan individu-individu sebagai pelaku usaha yang membutuhkan informasi bagi produknya.

3. Beberapa anggota KIM di Kecamatan Turi merupakan pelaku usaha yang sudah tergolong pada Kelompok Usaha Kecil dan Menengah. Mereka dapat membantu anggota yang lain untuk membantu mempercepat proses pemberian daya, sedangkan KIM di Kecamatan Gamping mendampingi kelompok pelaku usaha yang semua anggotanya masih tergolong pada Kelompok Usaha Mikro. Mereka masih tergantung pada pemberi daya dari pihak di luar kelompoknya sehingga proses pemberdayaan memerlukan waktu yang relatif lebih lama.

4. Peran Camat dan Kepala Seksi Ekonomi dan Pembangunan sebagai penasehat KIM di
Kecamatan Turi memiliki andil yang besar dalam proses pemberdayaan masyarakat.

5. Kecamatan Turi sebagai daerah wisata agro salak pondoh yang sudah terkenal dapat memberikan daya pada masyarakat bahwa mereka sebenarnya mempunyai potensi yang dapat dimanfaatkan untuk keluar dari ketidakberdayaan.

Apabila melihat Tabel 1. tentang program pemberdayaan yang telah dilakukan oleh KIKM Kertomandiri di Kecamatan Turi dan KIM di Kecamatan Gamping, maka kedua KIM tersebut mempunyai program yang sama dalam melakukan pemberdayaan masyarakat. Kegiatan studi banding di lokasi perkebunan strawberri di Ciwidey Bandung, audiensi dengan komisi B DRPD Kabupaten Sleman, dan liputan media merupakan kegiatan yang diadakan berkaitan dengan kemajuan yang diraih UMKM Kecamatan Turi. KIM berusaha untuk mengakses informasi, mengolah, menyampaikan informasi dan melakukan komunikasi kepada masyarakat untuk mendayagunakan informasi untuk kepentingan yang lebih bersifat ekonomi yang bertujuan untuk meningkatkan kesejahteraan masyarakat.

Ada sedikit perbedaan program pemberdayaan yang telah dilakukan KIM. KIM yang lebih maju memiliki kemudahan akses informasi dari berbagai sumber, mampu mengakses informasi, mendiskusikan, mengimplementasikan dalam berbagai kegiatan usaha sehingga dapat meningkatkan kesejahteraannya, terlibat aktif dalam kegiatan yang diselenggarakan Pemda Kabupaten Sleman, banyak memiliki jaringan kerjasama dengan institusi terkait, mempunyai kegiatan usaha yang lebih luas, dan mempunyai program pemberdayaan yang lebih banyak. Hal tersebut disebabkan oleh awal waktu KIM mulai terbentuk, ide/gagasan pembentukan, dan yang tidak kalah penting adalah orang-orang yang berperan sebagai motor penggerak KIM. Sebagai seorang motor penggerak harus mampu menjadi motivator yang dilandasi dengan rasa ikhlas, memiliki rasa peduli, dan menjadi fasilitator untuk membantu menyelesaikan permasalahan yang dihadapi para pelaku UMKM. 
Tabel 2. Program Pemberdayaan yang telah dilakukan KIM

\begin{tabular}{|c|c|c|c|}
\hline NO. & $\begin{array}{c}\text { PROGRAM } \\
\text { PEMBERDAYAAN }\end{array}$ & $\begin{array}{c}\text { KIKM KERTOMANDIRI di } \\
\text { KECAMATAN TURI } \\
\text { (KIM lebih maju) }\end{array}$ & $\begin{array}{c}\text { KIM di KECAMATAN } \\
\text { GAMPING } \\
\text { (KIM belum maju) } \\
\end{array}$ \\
\hline 1 & $\begin{array}{l}\text { Peningkatan Media akses } \\
\text { informasi }\end{array}$ & $\begin{array}{l}\text { Pertemuan rutin, media cetak dan } \\
\text { elektronik termasuk internet }\end{array}$ & $\begin{array}{l}\text { Belum mengadakan pertemuan } \\
\text { secara rutin, memanfaatkan medi } \\
\text { cetak dan elektronik }\end{array}$ \\
\hline 2 & Sosialisasi & $\begin{array}{l}\text { Kebijakan pemerintah, peluang usaha, } \\
\text { pengembangan dan pemberdayaan } \\
\text { KIM, Informasi yang harus segera } \\
\text { diketahui masyarakat }\end{array}$ & $\begin{array}{l}\text { Kebijakan pemerintah, peluang } \\
\text { usaha, Informasi yang harus sege } \\
\text { diketahui masyarakat }\end{array}$ \\
\hline 3 & $\begin{array}{l}\text { Keikutsertaan dalam kegiatan } \\
\text { pemerintahan }\end{array}$ & $\begin{array}{l}\text { Diudang dalam kegiatan sosialiasi oleh } \\
\text { berbagai dinas/instansi (implementasi } \\
\text { S.E. dari Humas Pemda) }\end{array}$ & $\begin{array}{l}\text { Diudang dalam kegiatan sosialias } \\
\text { oleh berbagai dinas/instansi } \\
\text { (implementasi S.E. dari Humas } \\
\text { Pemda) }\end{array}$ \\
\hline 4 & $\begin{array}{l}\text { Membuka jaringan ke } \\
\text { instansi/dinas/lembaga terkait. }\end{array}$ & $\begin{array}{l}\text { STIM YKPN, PT TELKOM, LIPPI, } \\
\text { Dinas Perindustrian }\end{array}$ & Dinas sosial \\
\hline 5 & Pelatihan & $\begin{array}{l}\text { Mendapat berbagai pelatihan sesuai } \\
\text { dengan kebutuhan anggota dan } \\
\text { masyarakat dari instansi/dinas terkait }\end{array}$ & $\begin{array}{l}\text { Pelatihan dari Dinas Perindustria: } \\
\text { pembuatan kacang telur dan kue } \\
\text { kering }\end{array}$ \\
\hline 6 & Pameran & $\begin{array}{l}\text { Mengikuti pameran potensi daerah di } \\
\text { Kabupaten, JEC dan dinas terkait dan } \\
\text { Nasional }\end{array}$ & $\begin{array}{l}\text { Mengikuti pameran potensi daera } \\
\text { di Kabupaten. }\end{array}$ \\
\hline 7 & Penguatan modal & $\begin{array}{l}\text { Pembentukan LKM, memperoleh } \\
\text { pinjaman uang dari STIM YKPN }\end{array}$ & $\begin{array}{l}\text { Program Pengembangan } \\
\text { Kecamatan (PPK) }\end{array}$ \\
\hline 8 & Pendampingan & Pada anggota & $\begin{array}{l}\text { Pada kelompok warga kurang } \\
\text { mampu dan WRSE }\end{array}$ \\
\hline 9 & Studi banding & $\begin{array}{l}\text { Perkebunan strawberry Ciwidey } \\
\text { Bandung }\end{array}$ & Belum pernah \\
\hline 10 & $\begin{array}{l}\text { Melakukan audiensi dengan } \\
\text { Komisi B DPRD Kab. Sleman }\end{array}$ & Telah diadakan dua kali & Belum pernah \\
\hline 11 & Liputan media & Koran, website, RRI dan TVRI & Belum pernah \\
\hline 12 & Pembuatan paket informasi & Belum dilakukan & Belum dilakukan \\
\hline 13 & Saran & $\begin{array}{l}\text { Agar pemerintah lebih peduli pada } \\
\text { KIM dengan menindaklanjuti program } \\
\text { pemberdayaan yang telah dilakukan } \\
\text { dan memberi kemudahan dan } \\
\text { kesempatan yang lebih longgar untuk } \\
\text { mengembangkan usaha para anggota } \\
\text { dan masyarakat. }\end{array}$ & $\begin{array}{l}\text { Kecamatan memperhatikan KIM } \\
\text { Pemda fasilitasi sarana dan } \\
\text { prasarana, Pemerintah ikut } \\
\text { mensosialisasikan keberadaan } \\
\text { KIM. }\end{array}$ \\
\hline
\end{tabular}

Sumber: wawancara dengan pengurus dan anggota kelompok, data diolah 


\section{Kesimpulan dan Rekomendasi}

1) Proses pemberdayaan masyarakat yang telah dilakukan oleh Kelompok Informasi Masyarakat di Kecamatan Turi dan di Kecamatan Gamping melalui tahapan sebagai berikut: a) memberikan penyadaran tentang arti pentingnya informasi; b) pengkapasitasan; c) pemberian daya; d) membuat rencana aksi dan implementasi; e) melakukan evaluasi.

2) Program Pemberdayaan yang telah dilakukan oleh KIM mencakup: (a) meningkatkan kualitas sumberdaya manusia melalui pelatihan; (b) pembuatan paket informasi; (c) mengikutsertakan KIM dalam kegiatan pemerintahan; (d) membuka jaringan KIM ke instansi terkait; (e) mengadakan studi banding; (f) peningkatan media akses informasi; (g) sosialisasi; (h) mengikuti kegiatan pameran; (i) penguatan modal; (j) pendampingan; (k) melakukan audiensi dengan Komisi DPRD; (l) liputan media.

3) Perbedaan program pemberdayaan yang telah dilakukan oleh KIM yang lebih maju dan belum maju disebabkan oleh tahun awal terbentuknya KIM, Ide/gagasan pembentukan, dan peran motor penggerak.

Program pemberdayaan dapat memberikan manfaat yang besar bagi kelompok masyarakat. Mereka dapat memperoleh informasi untuk mengakses ke sumber-sumber pembiayaan, peluang pasar, dan jaringan pemasaran yang berkaitan dengan bidang usahanya.

Hambatan yang dialami dalam aplikasi program pemberdayaan adalah sebagian masyarakat masih menganggap bahwa sudah menjadi tugas pemerintah untuk memfasilitasi kemudahan akses informasi yang diperlukan oleh masyarakat. Untuk mengatasi hal tersebut Humas Pemda Sleman bersama KIM yang terbentuk di setiap kecamatan, melakukan sosialisasi secara intensif tentang pentingnya informasi bagi masyarakat melalui proses pemberdayaan.

\section{Rekomendasi}

1. Perlu adanya penelitian lebih lanjut mengenai pemberdayaan KIM untuk menambah temuan baru tentang program pemberdayaan dengan mengambil banyak kasus.

2. Dalam praktek pemberdayaan masyarakat diperlukan:

a) peningkatan media akses informasi; b) pembuatan paket informasi; c) membuka akses ke sumber-sumber pembiayaan; d)peningkatan kegiatan sosialisasi.

\section{DAFTAR PUSTAKA}

Abimanyu, Anggito. Ed. (t.th). Pembangunan ekonomi dan pemberdayaan rakyat. Yogyakarta: PAU-SE UGM dan BPFE.

Adi, Isbandi Rukminto. (2008). Intervensi komunitas: pengembangan masyarakat sebagai upaya pemberdayaan masyarakat. Jakarta: Rajawali.

Darwanto, Herry. (2004). Pemberdayaan masyarakat pedesaan berbasiskan masyarakat terpencil. Majalah Perencanaan, September.

Dharmawan, Arya Hadi. Pendekatan-pendekatan pembangunan pedesaan dan pertanian: klasik dan kontemporer. http://www.psp3ipb.or.id/uploaded/Teori_Teori_Pembangunan_Klasik_ Kontemporer_2006.pdf. diakses 22 Oktober 2008.

Djunaedi, Achmad. (2007). Diseminasi informasi ke masyarakat. Handout mata kuliah Manajemen Dukungan Layanan Informasi Program S2 Manajamen Informasi \& Perpustakaan UGM.

Huraerah, Abu dan Purwanto (2006). Dinamika kelompok: konsep \& aplikasi. Bandung: Refika Aditama.

Indonesia. Departemen Komunikasi dan Informatika. Dirjen Sarana Komunikasi

dan Diseminasi Informasi. (2006). Kerangka acuan arah pengembangan dan pemberdayaan Kelompok Informasi Masyarakat (KIM). Jakarta: Dirjen Sarana Komunikasi dan Diseminasi Informasi.

Indonesia. Tim Penyusun Kamus Pusat Bahasa (2005). Kamus Besar Bahasa Indonesia. Jakarta: Balai Pustaka.

International Telecommunication Union. (2004). Multi purpose community

Telecentre network project for African women. 
http:/www.itu.int/wsis/stocktaking/scripts/docu ments asp?project $=1101998920$ \&lang $=$ en, 10 Maret 2009; 15.58 wib.

Isbandiah HS (2004). Jarkosmos: upaya pemberdayaan anggota masyarakat sebagai pelaku komunikasi. Makalah disampaikan pada Forum Dialog Jarkomsos di Yogyakarta, 24 Agustus 2004.

Ismawan, Bambang. (2003). Partisipasi dan dimensi keswadayaan: pengalaman LSM membangun keswadayaan masyarakat. Jurnal Ekonomi Rakyat, Vol. 2 (3) Mei 2003: p. 1-7.

Kartono, Derajat Tri. (2004). Pembentukan sistem ketahanan sosial melalui pemberdayaan masyarakat kelurahan. Surakarta: Sebelas Maret University Press.

Maika, Amelia. (2006). Kesejahteraan masyarakat Sumatera Selatan: analisis data survei aspek kehidupan rumah tangga Indonesia 1997 2000. Yogyakarta: Kerja sama Pusat Studi Kependudukan dan Kebijakan, Universitas Gadjah Mada dengan Partnership for Economic United States Agency for International Development.

Nugroho, Heru. (1997). Institusi-institusi mediasi sebagai sarana pemberdayaan masyarakat lapis bawah: studi kasus arisan di Bantul dan credit union di Timor-TimurAnalisis CSIS, Vol. 26 (1) Januari-Februari 1997: p. 99-112.

Nurcholis, Hanif. (2005). Teori dan praktik pemerintahan dan otonomi daerah. Jakarta: Grasindo, 2005.

Realyta, Silviana. (2007). Hubungan komposisi kelompok dengan sikap etnosentrik.

http://ibrary.usu.ac.id/index.php?option $=\mathrm{com}$ i ournals\&sf $=$ author\&keyword $=$ silviana $\% 20$ real yta\&exact $=1$ \&task = search

Ropingan. (2007). Peran KIM dalam meningkatkan kesejahteraan masyarakat di Kabupaten Ponorogo dan Kabupaten Lombok Barat. KOMMTI: Jurnal Penelitian Komunikasi, Media Massa dan Teknologi Informasi, Vol. 1 (3) November 2007: 217-238.

Rusadi, Udi. (2005). Pemberdayaan Kelompok Informasi Masyarakat (KIM) dalam penyebaran dan pelancaran arus informasi. Makalah disampaikan pada Forum Komunikasi Kelompok Informasi Masyarakat (KIM) di Yogyakarta, 1 September 2005.

Satriya, Eddy. (2004). WSIS dan pembangunan telematika nasional.
http://www.scribd.com/doc/2386392/WSISDAN-PEMBANGUNAN-TELEMATIKA-

NASIONAL?autodown $=$ pdf, diakses 10 Mare $2009 ; 16.50$.

Sulistiyani, Ambar Teguh (2004). Kemitraan dc model pemberdayaan. Yogyakarta:

GavaMedia.

Sumodiningrat, Gunawan. (1999). Pemberdayac masyarakat dan jarring pengaman sosic Jakarta: Gramedia.

World Bank. (2005). Measuring empowermer cross, disciplinary perspectives. Washingto D.C.: World Bank.

World Bank. (2006). Global trends and policit Washington, D.C.: World Bank.

Wrihatnolo, Randy R. dan Riant Nugrol Dwidjowijoto (2007). Manajem pemberdayaan: sebuah pengantar dan pandu. untuk pemberdayaan masyarakat. Jakarta: E] Media Komputindo.

Yin, Robert K. (19965)udi kasus (desain dan metode). Jakarta: RajaGrafindo Persada.

Yogyakarta.Badan Pusat Statistik. (2005). Kabupa Sleman dalam angka 2004. Yogyakarta: BPS

Yogyakarta. Badan Pusat Statistik (2008). Kabupa. Sleman dalam angka 2007. Sleman: BPS.

http://goorganik.com/mod.php?mod=publisher\&op iewarticle\&cid $=4 \&$ artid $=13,25-10-2008$; 14.00 .

http://www.slemankab.go.id,25-11-2008;13:15

http://www.ugm.ac.id. 17-10-2008; 13.40 